\title{
Antígenos de larva de Taenia solium em ELISA para diagnóstico da cisticercose bovina
}

[Taenia solium metacestode antigens in ELISA for the diagnosis of bovine cysticercosis]

\author{
L.L. Monteiro ${ }^{1}$ P.S.A. Pinto ${ }^{2 *}$ J.H.P. Salcedo ${ }^{2}$ J.V. Araújo $^{2}$ W.L.M. Santos ${ }^{3}$ P.R. Cecon $^{4}$ \\ ${ }^{1}$ Aluno de pós-graduação - UFV - Viçosa, MG \\ ${ }^{2}$ Departamento de Veterinária - UFV \\ Av. P.H. Rolfs, $\mathrm{s} / \mathrm{n}$ \\ 36570-000 - Viçosa, MG \\ ${ }^{3}$ Escola de Veterinária - UFMG - Belo Horizonte, MG \\ ${ }^{4}$ Departamento de Estatística - UFV - Viçosa, MG
}

\begin{abstract}
RESUMO
Foram avaliados alguns parâmetros inerentes ao ELISA, por meio de ensaios de reatividade de soroscontrole positivos e negativos para a cisticercose bovina com relação a três tipos de antígenos de larva de Taenia solium: total, de escólex e de membrana. As concentrações de antígeno de 0,$25 ; 0,5 ; 1 ; 2$ e $4 \mu \mathrm{g}$ por orifício, e as diluições de soro de 1:25, 1:50, 1:100 e 1:200, foram os parâmetros que menos influenciaram no desempenho do teste. A substância bloqueadora, o leite desnatado e as diluições de conjugado, 1:1.250, 1:2.500 e 1:5.000, representaram os melhores indicadores de desempenho do teste. Concluiu-se que essa combinação de critérios deve ser considerada no diagnóstico da cisticercose bovina, em atividades de rotina ou de padronização do referido teste, considerando os três antígenos de larva de $T$. solium estudados.
\end{abstract}

Palavras-chave: cisticercose bovina, ELISA, antígeno, Taenia solium

\begin{abstract}
Some parameters of ELISA were evaluated using positive and negative bovine sera for cysticercosis and three types of antigens of Taenia solium larvae: total, scolex and membrane. The antigen concentrations $(0.25 ; 0.5 ; 1 ; 2$ and $4 \mu \mathrm{g} /$ well $)$ and the serum dilutions $(1: 25,1: 50,1: 100$ and $1: 200)$ were the parameters that influenced less the test performance; while blocking substance, skimmed milk, and conjugate dilutions, 1:1.250, 1:2.500 and 1:5.000 were the best indexes of the test performance. It was concluded that this combination of criteria should be considered in the diagnosis of bovine cysticercosis, in routine diagnosis and for the ELISA test standardization.
\end{abstract}

Keywords: bovine cysticercosis, ELISA, antigen, Taenia solium.

\section{INTRODUÇÃO}

A cisticercose bovina é uma enfermidade de distribuição cosmopolita e caráter zoonótico, de grande importância em regiões onde a população apresenta baixo nível socioeconômico. Sua prevalência é obtida a partir de dados fornecidos pelos serviços de inspeção em matadouros (Queiroz et al., 2000).
A sensibilidade do método de inspeção post mortem utilizado nos estabelecimentos de abate na deteç̧ão de carcaças parasitadas pelo Cysticercus bovis vem sendo questionada. As críticas estão relacionadas ao fato de que a inspeção se baseia na detecção de cistos apenas em sítios específicos no animal; por isso, podem ocorrer resultados falso-negativos em bovinos que apresentam cistos em outros locais da

Recebido em 2 de maio de 2005

Aceito em 21 de agosto de 2006

*Autor para correspondência (corresponding author)

E-mail:pintopsa@ufv.br 
carcaça. Além disso, não se deve desconsiderar o fato de que cistos mortos ou calcificados (esbranquiçados) são mais fáceis de serem identificados em relação aos cistos vivos (rosapálidos), que podem passar desapercebidos durante a inspeção (Onyango-Abuje et al., 1996). Assim, torna-se necessário desenvolver métodos mais eficazes e seguros, que aprimorem a eficiência do diagnóstico, como o apoio à detecção da cisticercose em matadouros (Queiroz et al., 2000).

Algumas dificuldades também são apontadas nos métodos alternativos, indicando, no caso dos imunológicos, a criteriosa seleção do material a ser empregado, entre estes o tipo de antígeno. Geerts et al. (1981) afirmaram que, para o diagnóstico da cisticercose, é necessária uma técnica de elevada sensibilidade, devido ao alto grau de adaptação da larva de Taenia saginata ao hospedeiro, que resulta em uma baixa produção de anticorpos. Além disso, em condições naturais, a maioria dos bovinos exibe baixa taxa de infecção.

Ao compararem antígenos de escólex de larva de $T$. solium com os antígenos totais de larvas de $T$. saginata e de $T$. crassiceps em ELISA indireto para diagnóstico da cisticercose bovina, Minozzo et al. (2004) verificaram melhor desempenho do teste, quando se utilizou o antígeno de Taenia solium, em substituição aos demais; o que sinaliza para a sua melhor indicação em ensaios de padronização.

Este trabalho teve por objetivo avaliar alguns parâmetros de padronização do ELISA para o diagnóstico da cisticercose bovina, utilizando antígenos de larva de $T$. solium, visando ao ajuste do ensaio para uma proposta de aplicação prática.

\section{MATERIAL E MÉTODOS}

Foram utilizados soros de dois bovinos leiteiros criados sob estabulação e infectados experimentalmente aos dois meses de idade com cerca de 100.000 ovos de $T$. saginata cada e soros de seis bovinos negativos para cisticercose, mantidos em isolamento com alimentação controlada desde o nascimento.
Os cisticercos utilizados no preparo dos antígenos testados foram obtidos a partir da musculatura de suíno naturalmente infectado, proveniente de uma região endêmica para cisticercose, e removidos com o auxílio de um bisturi. Após o congelamento do material obtido, procedeu-se ao preparo dos respectivos antígenos, total (cisticerco inteiro), de escólex e de membrana de larva de T. Solium, por meio das seguintes etapas: desidratação overnight dos cisticercos, do escólex ou da membrana por liofilização; trituração do material desidratado em gral; adição de solução salina $0,15 \mathrm{M}$ para obtenção de proporção de $10 \%$ (pó); homogeneização em homogeneizador de tecido tipo Potter, em banho de gelo; centrifugação a $17.400 \mathrm{~g} / 30 \mathrm{~min} / 4^{\circ} \mathrm{C}$; separação do sobrenadante para adição de inibidor de protease PMSF; e estocagem a $-20^{\circ} \mathrm{C}$.

O ELISA foi realizado segundo a técnica empregada por Pinto et al. (2000).

Os ensaios de padronização foram realizados em três fases, analisando-se os três antígenos separadamente. Cada fase caracterizou-se pela avaliação simultânea de um ou mais parâmetros que foram: o tipo de substância bloqueadora (três critérios), a concentração do antígeno (cinco critérios), soro (quatro critérios) e conjugado (sete critérios). A variável resposta foi caracterizada como valor de densidade óptica, representada pela média das diferenças obtidas entre as densidades ópticas (DO) dos soroscontrole positivos e dos negativos nos ensaios de ELISA. Os melhores critérios de cada parâmetro pesquisado foram definidos pelo maior valor de densidade óptica.

No início dos testes de padronização, os períodos de incubação e a condição de bloqueio dos sítios reativos das placas foram fixados, convencionalmente, baseando-se na seleção prévia feita por Pinto et al. (2000) para o diagnóstico da cisticercose suína.

Na fase 1, avaliaram-se, por meio de titulação em bloco, cinco concentrações do antígeno, 0,$25 ; 0,5$; 1; 2 e $4 \mu \mathrm{g}$ por orifício, e quatro diluições de soro, $1: 25 ; 1: 50 ; 1: 100$; e 1:200. Foram utilizados dois soros-controle positivos e dois soros-controle negativos em diluições seriadas (duas vezes), que variaram de 1:25 a 1:200. Nessa fase, a diluição do conjugado foi de 1:5000. 
$\mathrm{Na}$ fase 2, testou-se o conjugado, partindo das melhores combinações de concentração de antígeno e diluições de soro verificadas na fase 1. Foram utilizados dois soros-controle positivos e quatro soros-controle negativos e as seguintes diluições seriadas (duas vezes) de conjugado: 1:625; 1:1.250; $1: 2.500 ; 1: 5.000 ; 1: 10.000 ; 1: 20.000$ e $1: 40.000$.

$\mathrm{Na}$ fase 3, avaliou-se o tipo de substância bloqueadora: gelatina $1 \%$, albumina $1 \%$ e leite desnatado 5\%. Nessa fase, o teste foi realizado com as melhores condições do antígeno, soros e conjugado, definidas nas etapas anteriores, considerando dois soros-controle positivos e seis soros-controle negativos.

Os resultados foram analisados por meio do programa de análises estatísticas SAEG (Sistema..., 2005). Os dados foram submetidos à análise de variância e às médias comparadas utilizando-se o teste Tukey, adotando-se o nível de $5 \%$ de probabilidade. $\mathrm{Na}$ análise dos parâmetros e critérios, cujos dados não indicaram homogeneidade de variância, utilizou-se o teste não-paramétrico Kruskal-Wallis.

\section{RESULTADOS E DISCUSSÃO}

Quando se utilizou a concentração de $0,25 \mu \mathrm{g}$ do antígeno total por orifício, observou-se baixo desempenho do ELISA, entretanto houve aumento significativo do valor de DO para as concentrações maiores, sem ocorrer diferença entre estas (Tab. 1). Minozzo et al. (1994) não encontraram diferença significativa entre as concentrações 0,25 e $0,5 \mu \mathrm{g}$ do antígeno total por orifício, indicando a necessidade de ampliação dos estudos da influência desse parâmetro no desempenho do teste.

Para os ensaios das fases seguintes de titulação em bloco de conjugado e soro e de avaliação da substância bloqueadora, entre as melhores identificadas nessa pesquisa, escolheu-se a concentração de $1 \mu \mathrm{g}$ de antígeno por orifício das placas de ELISA. Nas condições de melhor desempenho do ELISA, as diferentes diluições de soro apresentaram valores de DO elevados e estatisticamente semelhantes, quando se utilizou o antígeno total de larva de T. solium.

As diluições 1:1.250, 1:2.500 e 1:5.000 de conjugado foram as que mostraram os maiores valores de DO para o antígeno total de larva de $T$. solium (Tab. 2).

Tabela 1. Densidades ópticas ao ELISA segundo os soros-controle positivos e negativos, em função de diferentes diluições dos soros e concentrações ( $\mu \mathrm{g} /$ orifício) do antígeno total de larva de T. solium

\begin{tabular}{ccccc} 
Concentração do & \multicolumn{4}{c}{ Diluição do soro } \\
\cline { 2 - 5 } antígeno & $1: 25$ & $1: 50$ & $1: 100$ & $1: 200$ \\
\hline 0,25 & $0,001 \mathrm{~b}$ & $0,006 \mathrm{~b}$ & $0,008 \mathrm{~b}$ & $0,006 \mathrm{~b}$ \\
0,5 & $0,201 \mathrm{aA}$ & $0,217 \mathrm{aA}$ & $0,197 \mathrm{aA}$ & $0,160 \mathrm{a}$ \\
1 & $0,248 \mathrm{aA}$ & $0,232 \mathrm{aA}$ & $0,238 \mathrm{aA}$ & $0,234 \mathrm{a}$ \\
2 & $0,163 \mathrm{aB}$ & $0,246 \mathrm{aAB}$ & $0,307 \mathrm{aA}$ & $0,301 \mathrm{aA}$ \\
4 & $0,221 \mathrm{aA}$ & $0,271 \mathrm{aA}$ & $0,307 \mathrm{aA}$ & $0,302 \mathrm{a}$ \\
\hline
\end{tabular}

Médias seguidas por letras minúsculas distintas na coluna ou maiúsculas distintas na linha diferem entre si pelo teste Tukey $(\mathrm{P}<0,05)$.

Tabela 2. Densidades ópticas de soros-controle positivos e negativos em função de diferentes diluições de conjugado e diluições de soros para o antígeno total de larva de T. solium

\begin{tabular}{ccccc}
\hline Diluição do & \multicolumn{4}{c}{ Diluição do soro } \\
\cline { 2 - 4 } conjugado & $1: 25$ & $1: 50$ & $1: 100$ & $1: 200$ \\
\hline $1: 625$ & $0,079 \mathrm{~cd}$ & $0,112 \mathrm{bc}$ & $0,093 \mathrm{bcd}$ & $0,055 \mathrm{bc}$ \\
$1: 1.250$ & $0,131 \mathrm{abc}$ & $0,220 \mathrm{ab}$ & $0,172 \mathrm{ab}$ & $0,175 \mathrm{a}$ \\
$1: 2.500$ & $0,207 \mathrm{ab}$ & $0,252 \mathrm{a}$ & $0,230 \mathrm{a}$ & $0,250 \mathrm{a}$ \\
$1: 5.000$ & $0,253 \mathrm{a}$ & $0,200 \mathrm{ab}$ & $0,164 \mathrm{abc}$ & $0,113 \mathrm{abc}$ \\
$1: 10.000$ & $0,101 \mathrm{bc}$ & $0,118 \mathrm{abc}$ & $0,066 \mathrm{bcd}$ & $0,056 \mathrm{bc}$ \\
$1: 20.000$ & $0,101 \mathrm{bc}$ & $0,065 \mathrm{~cd}$ & $0,058 \mathrm{~cd}$ & $0,050 \mathrm{bc}$ \\
$1: 40.000$ & $0,053 \mathrm{~cd}$ & $0,030 \mathrm{~cd}$ & $0,039 \mathrm{de}$ & $0,012 \mathrm{~cd}$ \\
\hline
\end{tabular}

Médias seguidas por letras distintas na coluna diferem entre si pelo teste Kruskal-Wallis $(\mathrm{P}<0,05)$. 
O leite desnatado a $5 \%$ proporcionou valores elevados de $\mathrm{DO}$, diferenciando-se $(\mathrm{P}<0,05)$ das outras substâncias de bloqueio, albumina e gelatina, nas diversas diluições de soros e tipos de antígenos testados (Tab. 3, 4 e 5).
Não houve diferença $(\mathrm{P}>0,05)$ entre as diferentes diluições de soros e concentrações de antígeno testadas ao utilizar o antígeno de escólex e entre as diluições de 1:25 e 1:50 com o antígeno de membrana de larva de T. solium (Tab. 6 e 7).

Tabela 3. Densidades ópticas de soros-controle positivos e negativos, em função de diferentes substâncias bloqueadoras e diluições de soros para o antígeno total de larva de T. solium

\begin{tabular}{ccccc}
\hline Substância & \multicolumn{4}{c}{ Diluição do soro } \\
\cline { 2 - 5 } bloqueadora & $1: 25$ & $1: 50$ & $1: 100$ & $1: 200$ \\
\hline Leite desnatado & $0,225 \mathrm{a}$ & $0,222 \mathrm{a}$ & $0,188 \mathrm{a}$ & $0,190 \mathrm{a}$ \\
Albumina & $0,122 \mathrm{a}$ & $0,097 \mathrm{~b}$ & $0,075 \mathrm{~b}$ & $0,073 \mathrm{~b}$ \\
Gelatina & $0,013 \mathrm{~b}$ & $0,056 \mathrm{~b}$ & $0,085 \mathrm{~b}$ & $0,106 \mathrm{~b}$ \\
\hline
\end{tabular}

Médias seguidas por letras distintas na coluna diferem entre si pelo teste Kruskal-Wallis $(\mathrm{P}<0,05)$.

Tabela 4. Densidades ópticas de soros-controle positivos e negativos em função de diferentes substâncias bloqueadoras e diluições de soros para o antígeno de escólex de larva de T. solium

\begin{tabular}{ccccc}
\hline Substância & \multicolumn{4}{c}{ Diluição do soro } \\
bloqueadora & $1: 25$ & $1: 50$ & $1: 100$ & $1: 200$ \\
\hline Leite desnatado & $0,257 \mathrm{a}$ & $0,176 \mathrm{a}$ & $0,150 \mathrm{a}$ & $0,124 \mathrm{a}$ \\
Albumina & $0,136 \mathrm{~b}$ & $0,085 \mathrm{~b}$ & $0,076 \mathrm{~b}$ & $0,054 \mathrm{a}$ \\
Gelatina & $0,022 \mathrm{c}$ & $0,068 \mathrm{~b}$ & $0,071 \mathrm{~b}$ & $0,078 \mathrm{a}$ \\
\hline
\end{tabular}

Médias seguidas por letras distintas na coluna diferem entre si pelo teste Kruskal-Wallis $(\mathrm{P}<0,05)$.

Tabela 5. Densidades ópticas de soros-controle positivos e negativos, em função de diferentes substâncias bloqueadoras e diluições de soros para o antígeno de membrana de larva de T. solium

\begin{tabular}{ccccc}
\hline Substância & \multicolumn{4}{c}{ Diluição do soro } \\
bloqueadora & $1: 25$ & $1: 50$ & $1: 100$ & $1: 200$ \\
\hline Leite desnatado & $0,309 \mathrm{a}$ & $0,268 \mathrm{a}$ & $0,244 \mathrm{a}$ & $0,166 \mathrm{~A}$ \\
Albumina & $0,262 \mathrm{a}$ & $0,260 \mathrm{a}$ & $0,224 \mathrm{a}$ & $0,147 \mathrm{~A}$ \\
Gelatina & $0,012 \mathrm{~b}$ & $0,043 \mathrm{~b}$ & $0,037 \mathrm{~b}$ & $0,059 \mathrm{~B}$ \\
\hline
\end{tabular}

Médias seguidas por letras minúsculas distintas na coluna diferem entre si pelo teste Kruskal-Wallis $(\mathrm{P}<0,05)$.

Médias seguidas por letras maiúsculas distintas na coluna diferem entre si pelo teste Tukey $(\mathrm{P}<0,05)$.

Tabela 6. Densidades ópticas ao ELISA de soros-controle positivos e negativos, em função de diferentes diluições dos soros e concentrações ( $\mu \mathrm{g} /$ orifício) do antígeno de escólex de larva de T. solium

\begin{tabular}{ccccc}
\hline \multirow{2}{*}{$\begin{array}{c}\text { Concentração do } \\
\text { antígeno }\end{array}$} & \multicolumn{4}{c}{ Diluição do soro } \\
\cline { 2 - 4 } & $1: 25$ & $1: 50$ & $1: 100$ & $1: 200$ \\
0,25 & 0,191 & 0,126 & 0,095 & 0,077 \\
0,5 & 0,180 & 0,179 & 0,131 & 0,138 \\
1 & 0,224 & 0,219 & 0,165 & 0,153 \\
2 & 0,214 & 0,242 & 0,229 & 0,215 \\
4 & 0,178 & 0,170 & 0,147 & 0,107 \\
\hline
\end{tabular}

Não houve diferença entre os valores $(\mathrm{P}>0,05)$.

Tabela 7. Densidades ópticas ao ELISA de soros-controle positivos e negativos, em função de diferentes diluições dos soros e concentrações ( $\mu \mathrm{g} /$ orifício) do antígeno de membrana de larva de T. solium

\begin{tabular}{ccccc}
\hline \multirow{2}{*}{$\begin{array}{c}\text { Concentração do } \\
\text { antígeno }\end{array}$} & $1: 25 \mathrm{a}$ & $1: 50 \mathrm{a}$ & $1: 100$ & $1: 200$ \\
\cline { 2 - 5 } & $0,203 \mathrm{a}$ & $0,17 \mathrm{a} 6$ & $0,092 \mathrm{~b}$ & $0,101 \mathrm{~b}$ \\
0,25 & $0,307 \mathrm{a}$ & $0,229 \mathrm{a}$ & $0,177 \mathrm{ab}$ & $0,105 \mathrm{~b}$ \\
0,5 & $0,251 \mathrm{a}$ & $0,272 \mathrm{a}$ & $0,252 \mathrm{a}$ & $0,166 \mathrm{ab}$ \\
2 & $0,266 \mathrm{a}$ & $0,309 \mathrm{a}$ & $0,289 \mathrm{a}$ & $0,221 \mathrm{a}$ \\
4 & $0,265 \mathrm{a}$ & $0,280 \mathrm{a}$ & $0,273 \mathrm{a}$ & $0,231 \mathrm{a}$ \\
\hline
\end{tabular}

Médias seguidas por letras distintas na coluna diferem entre si pelo teste Tukey $(\mathrm{P}<0,05)$. 
As diluições de conjugado 1:1.250, 1:2.500 e 1:5.000 também se confirmaram como as que proporcionaram maiores valores de DO nos ensaios com os antígenos de escólex e membrana de larva de T. solium. (Tab. 8 e 9). Nesta pesquisa, optou-se pela diluição 1:5.000 para prosseguir a padronização, porque não houve diferença estatística $(\mathrm{P}>0,05)$ entre essas três diluições e o seu uso permite maior economia de conjugado, um dos reagentes que mais onera o teste.

Tabela 8. Densidades ópticas de soros-controle positivos e negativos, em função de diferentes diluições de conjugado e diluições de soros para o antígeno de escólex de larva de T. solium

\begin{tabular}{ccccc}
\hline Diluição do & \multicolumn{4}{c}{ Diluição do soro } \\
\cline { 2 - 5 } conjugado & $1: 25$ & $1: 50$ & $1: 100$ & $1: 200$ \\
\hline $1: 625$ & $0,075 \mathrm{bc}$ & $0,110 \mathrm{ab}$ & $0,122 \mathrm{abc}$ & $0,122 \mathrm{abc}$ \\
$1: 1.250$ & $0,160 \mathrm{ab}$ & $0,211 \mathrm{a}$ & $0,236 \mathrm{a}$ & $0,188 \mathrm{ab}$ \\
$1: 2.500$ & $0,259 \mathrm{a}$ & $0,242 \mathrm{a}$ & $0,231 \mathrm{ab}$ & $0,215 \mathrm{a}$ \\
$1: 5.000$ & $0,247 \mathrm{a}$ & $0,220 \mathrm{a}$ & $0,156 \mathrm{abc}$ & $0,120 \mathrm{abc}$ \\
$1: 10.000$ & $0,068 \mathrm{bc}$ & $0,071 \mathrm{bc}$ & $0,060 \mathrm{bc}$ & $0,049 \mathrm{bc}$ \\
$1: 20.000$ & $0,051 \mathrm{bc}$ & $0,041 \mathrm{bc}$ & $0,032 \mathrm{~cd}$ & $0,041 \mathrm{bc}$ \\
$1: 40.000$ & $0,022 \mathrm{c}$ & $0,023 \mathrm{c}$ & $0,022 \mathrm{~d}$ & $0,015 \mathrm{~cd}$ \\
\hline
\end{tabular}

Médias seguidas por letras distintas na coluna diferem entre si pelo teste Kruskal-Wallis $(\mathrm{P}<0,05)$.

Tabela 9. Densidades ópticas de soros-controle positivos e negativos, em função de diferentes diluições de conjugado e diluições de soros para o antígeno de membrana de larva de T. solium

\begin{tabular}{ccccc}
\hline \multirow{2}{*}{$\begin{array}{c}\text { Diluição do } \\
\text { conjugado }\end{array}$} & $1: 25$ & $1: 50$ & $1: 100$ & $1: 200$ \\
\cline { 2 - 5 } & $0,054 \mathrm{bc}$ & $0,090 \mathrm{bc}$ & $0,116 \mathrm{abc}$ & $0,111 \mathrm{abc}$ \\
$1: 625$ & $0,132 \mathrm{ab}$ & $0,203 \mathrm{ab}$ & $0,208 \mathrm{ab}$ & $0,200 \mathrm{ab}$ \\
$1: 1.250$ & $0,257 \mathrm{a}$ & $0,274 \mathrm{a}$ & $0,272 \mathrm{a}$ & $0,213 \mathrm{a}$ \\
$1: 2.500$ & $0,286 \mathrm{a}$ & $0,251 \mathrm{a}$ & $0,198 \mathrm{ab}$ & $0,122 \mathrm{abc}$ \\
$1: 5.000$ & $0,163 \mathrm{ab}$ & $0,170 \mathrm{ab}$ & $0,089 \mathrm{bc}$ & $0,068 \mathrm{bc}$ \\
$1: 10.000$ & $0,113 \mathrm{bc}$ & $0,084 \mathrm{bc}$ & $0,036 \mathrm{~cd}$ & $0,041 \mathrm{~cd}$ \\
$1: 20.000$ & $0,049 \mathrm{bc}$ & $0,039 \mathrm{c}$ & $0,021 \mathrm{~cd}$ & $0,017 \mathrm{~cd}$ \\
$1: 40.000$ & $5 \mathrm{~cd}$ &
\end{tabular}

Médias seguidas por letras distintas na coluna diferem entre si pelo teste Kruskal-Wallis $(\mathrm{P}<0,05)$.

\section{CONCLUSÕES}

O desempenho do ELISA independe das concetrações de antígeno e das diluições de soro usadas. O leite desnatado e as diluições de conjugado de $1: 1.250, \quad 1: 2.500$ e $1: 5.000$ representam os melhores critérios indicadores de desempenho do teste, considerando os três antígenos de larva de $T$. solium estudados. Essa combinação de critérios, segundo os parâmetros estudados, deve ser valorizada no diagnóstico da cisticercose bovina por meio do ELISA, utilizando antígenos de larvas de Taenia solium, seja em atividades de rotina seja como base para iniciar novas pesquisas de padronização do referido teste.

\section{REFERÊNCIAS BIBLIOGRÁFICAS}

GEERTS, S.; KUMAR, V.; CEULEMANS, F.; NORTELMANS, J. Serodiagnosis of Taenia saginata cysticercosis in experimentally and naturally infected cattle by enzyme linked immunosorbent assay. Res. Vet. Sci., v.30, p.288-293, 1981.
MINOZZO, J.C.; THOMAZ-SOCCOL, V.; OLORTEGUI, C.C. et al. Teste imunoenzimático (enzyme- linked immunosorbent assay) para diagnóstico da cisticercose bovina e estudo da cinética de produção de anticorpos contra- Cysticercus bovis. Cien. Rural, v.34, p.857-864, 2004.

ONYANGO-ABUJE, J.A. ; HUGHES, G.; OPICHA, M. et al. Diagnosis of Taenia saginata cysticercosis in Kenyan cattle by antibody and antigen ELISA. Vet. Parasitol., v.61, p.221-230, 1996.

PINTO, P.S.A.; VAZ, A.J.; GERMANO, P.M.L. et al. Performance of the ELISA test for swine cysticercosis using antigens of Taenia solium and Taenia crassiceps cysticerci. Vet. Parasitol., v.88, p.127-130, 2000.

QUEIROZ, R.P.V.; SANTOS, W.L.M.; BARBOSA, H.V. et al. A importância do diagnóstico da cisticercose bovina. Rev. Hig. Alim., v.14, p.12-15, 2000.

SISTEMA DE ANÁLISES ESTATÍSTICAS E GENÉTICAS - SAEG 9.0 , Viçosa: UFV, 2005. 